\title{
Determination of Cadmium and Lead in Northern Pike from the Missouri River
}

\author{
Jennifer Even and Shahrokh Ghaffari* \\ Ohio University-Zanesville \\ Zanesville, Ohio 43701 USA
}

Received: March 15, 2011 Accepted: September 1, 2011

\begin{abstract}
Lead and cadmium are trace metals which accumulate in the body and are extremely toxic in living organisms. The purpose of this study was to find organ(s) with the greatest concentrations of these elements. In this study liver, gill, intestines, and kidney of five samples of Northern Pikes were analyzed. After the organs were dried and digested using nitric acid the anodic stripping voltammetry method was employed to analyze this samples. This method was used for its low detection limit of $10^{-9}$ to $10^{-10} \mathrm{M}$. However, no trace of either lead or cadmium was found in all 60 samples analyzed. Lack of detectable amount of both lead and cadmium is attribute to; first, Northern Pikes are not bottom dweller and thus would not be highly exposed to sediments that most commonly contain trace metals, second, the absence of a major industry which typically produces these contaminates in this area.
\end{abstract}

\section{INTRODUCTION}

Lead and cadmium are trace elements which, because they serve no known useful purpose in the body of any living organism, have serious and varied adverse effects. As a result, lead and cadmium may accumulate in particular organs of the body. In order to prevent harmful exposure, awareness of sources and uses, modes of entry into the body, toxic effects and safe limits must be established. Special attention is often given to exposure in children, because it may result in developmental problems.

Since ancient Roman times, about 7,000 B.C., lead has been known to man and used for glazing pottery, solder, ornaments, coins, piping, and cooking utensils. Likewise, poisoning from these items has been recognized for about 2,500 years. Not all lead that is ingested is absorbed, much of it passes directly through and is excreted in feces. Some is likewise absorbed by the liver and excreted in bile. The lead that is absorbed is most often bioconcentrated, gathered in one particular organ or tissue, and is also bioaccumulated, which means that increasing amounts build

* Corresponding author up in the body [1,2]. Eventually at one point symptoms and disability occur. In children, this point has been established by the Center for Disease Control as 25 microliters/deciliter for lead [3-6].

Cadmium affects various organs such as bones, brain, kidney and nervous system Research on the long term toxic effects and accumulation patterns of cadmium in fish $[7,8]$, also lend support to the effects on humans $[9,10]$.

Much independent research indicates the accumulation of these heavy metals in fish including Northern Pike [1113]. Because fishes "have the ability to accumulate heavy metals in their tissues by the absorption along the gill surface and gut tract wall to higher levels which are several hundred times more than the concentration of metals in their surrounding water medium," testing was done on the gill, kidney, liver and intestines based on studies by Suresh, et. al [1,7]. Although other factors, such as salinity, $\mathrm{pH}$, temperature, and water hardness are thought to affect lead and cadmium accumulation, these factors are the same for all samples and therefore we disregard these considerations at this time. 


\begin{tabular}{|c|c|c|c|c|}
\hline Fish No. & Sex & Weight (g) & TL (mm) & FL (mm) \\
\hline 1 & Female & 2353 & 730 & 695 \\
\hline 2 & Male & 1446 & 620 & 580 \\
\hline 3 & Female & 2495 & 660 & 635 \\
\hline
\end{tabular}

Table 1. Total length $(\mathrm{TL})$ and fork length $(\mathrm{FL})$ for three Northern Pike samples.

\begin{tabular}{|c|c|c|c|c|c|}
\hline Fish No. & $\begin{array}{l}\text { Tissue } \\
\text { Sample }\end{array}$ & Sample No. & $\begin{array}{l}\text { Wet Weight } \\
\text { (g) }\end{array}$ & $\begin{array}{l}\text { Dry Weight } \\
\text { (g) }\end{array}$ & $\%$ Water \\
\hline \multirow{4}{*}{ Fish \#1 } & Intestines & 1 & 30.48 & 5.39 & 82.3 \\
\hline & Liver & 2 & 49.24 & 10.05 & 79.6 \\
\hline & Gill & 3 & 21.95 & 4.97 & 77.4 \\
\hline & Kidney & 4 & 8.77 & 1.70 & 80.6 \\
\hline & & & & & \\
\hline \multirow{4}{*}{ Fish \#2 } & Intestines & 1 & 18.50 & 4.09 & 77.9 \\
\hline & Liver & 2 & 29.37 & 8.14 & 72.3 \\
\hline & Gill & 3 & 15.38 & 3.63 & 76.4 \\
\hline & Kidney & 4 & 5.99 & 1.19 & \\
\hline & & & & & \\
\hline \multirow{4}{*}{ Fish \#3 } & Intestines & 1 & 35.20 & 9.56 & 75.1 \\
\hline & Liver & 2 & 75.59 & 17.94 & 76.3 \\
\hline & Gill & 3 & 27.41 & 6.34 & 76.9 \\
\hline & Kidney & 4 & 13.53 & 2.71 & 80.0 \\
\hline
\end{tabular}

Table 2. Organ weight [mass], wet and dry, for the three samples.

In an effort to better understand, independent research was done to investigate which organ/body part was the major accumulator of lead and cadmium in Northern Pike (Esox lucius). The methods and results will be discussed.

\section{EXPERIMENTAL PROCEDURE}

The samples were collected from two sites on the Missouri River, the Apple Tree Boat Basin and the Springfield Boat Basin, both located near Springfield, South Dakota. Laboratory methods began by taking some basic measurements. The weight of the fish were taken using a digital hand-held scale. Next, the total length (TL) and fork length (FL) were taken using a meter stick, measuring to the nearest millimeter (Table 1). The caution was used to prevent any contamination of tools used for dissection and other purposes were properly washed and carefully handled.

The next step of preparation involved the acquisition of the desired organs: gill, kidney, intestines, and liver. An incision was made from the anus to just below the mouth. Each individual organ was removed separately and placed in a Petri dish containing deionized distilled water to maintain freshness. The gills were removed completely, including gill arches. Next the intestine was removed from the pyloric valve (at the end of the stomach) to the anus. After removal of the intestines, they were opened completely and all contents were first wiped out with a paper towel and then thoroughly washed out with deionized distilled water. The entire liver was then removed. The kidney was removed from a point approximately midway through the abdominal cavity posteriorly to the posterior wall of the abdominal cavity. The anterior portion was too fragile to be completely removed. The time from organ removal to wet weighing was approximately 20-40 minutes (Table 2).

After wet weight was taken, the organs of the first two sample fish were placed into individual plastic bags which were sealed and floated in a beaker containing water. The beaker was placed in a refrigerator for overnight storage. 


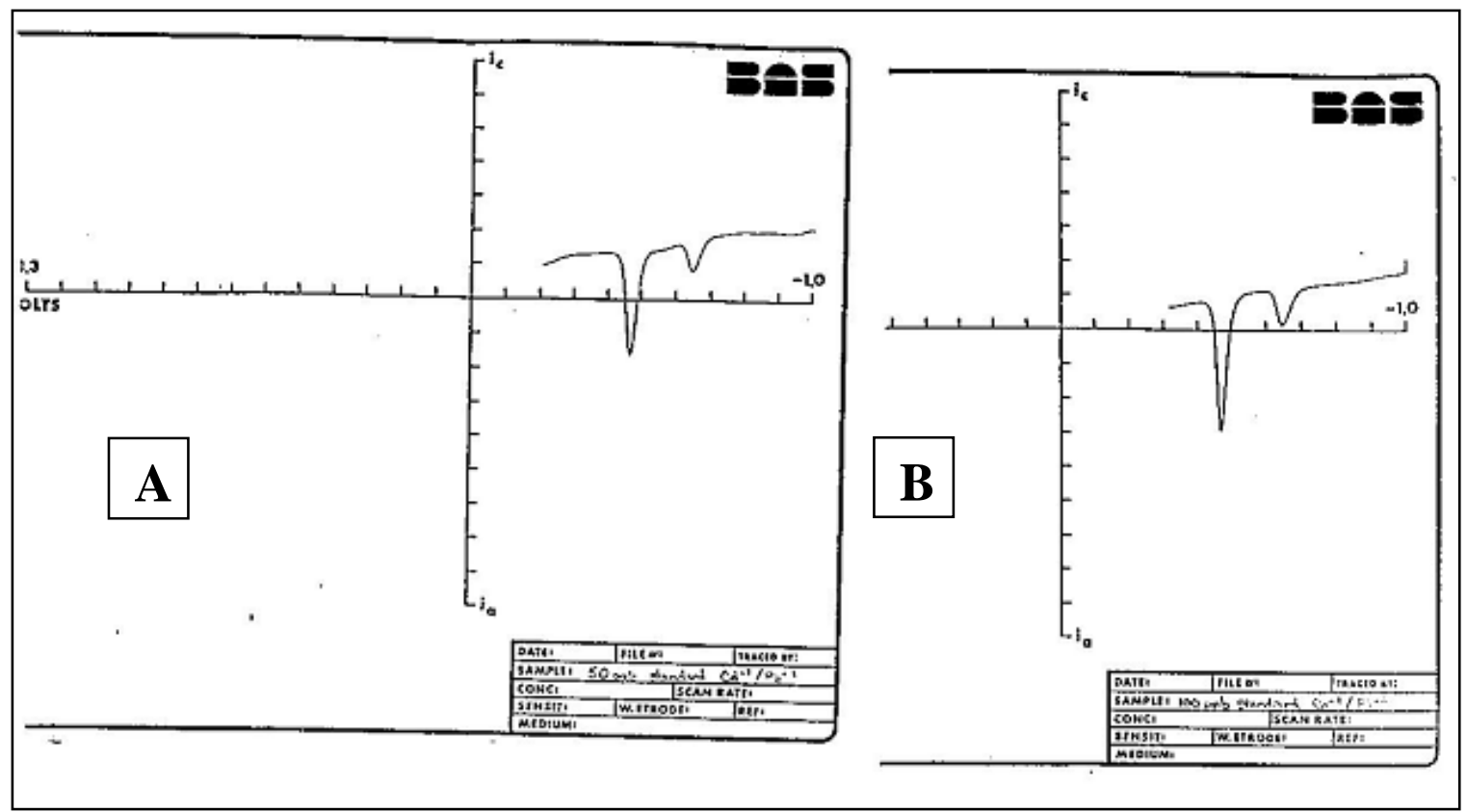

Figure 1. ASV Scan of Sample of Standard Solutions, A) $50 \mathrm{ppb} \mathrm{Pb}^{2+} / \mathrm{Cd}^{2+}$, B) $100 \mathrm{~Pb}^{2+} / \mathrm{Cd}^{2+}$.

Organs were placed in separate drying crucibles, labeled, and put into an oven to dry for 48 hours at 80 degrees Celsius. After 48 hours the total weight was taken again and the dry weights were then calculated. From the two weights, wet and dry, the percent of water in the wet sample could be calculated. The results are tabulated in Table 2.

Numerous analysis methods are utilized in the detection of trace metals. Because the desired concentration levels in this research project involve biological tissue/organ concentrations, Anodic stripping voltammetry (ASV), was used due to its sensitivity and low detection limits for lead and cadmium (5-10 ppb).

To get the dried fish samples into a liquid phase for analysis, a modified version of the $\mathrm{HNO}_{3}$ Solubilization of Biological Tissues (SOP 12.04, 1986) was used. A dry weight sample $(0.100$ - 3.00 grams) was taken in triplicate (three separate samples) of each organ, and placed in a digestion tube. Next, $5 \mathrm{mLs}$ of sub-boiled concentrated $\mathrm{HNO}_{3}$ was added to the digestion tube and covered with plastic wrap and allowed to stand overnight. The following day, the plastic wrap was removed and replaced with a Teflon cap liner, followed by a piece of plastic wrap and finally, a Crown bottle cap. The bottle cap was secured by using a mechanical capping device. The digestion tubes, once capped, were placed in a water bath at a temperature of 70 degrees Celsius for 48 hours. It was necessary that water be added at about the 24 hour mark to maintain a water level above the contents in the tubes.

After the 48 hours, the tubes were removed and cooled to room temperature. The seal was broken by using a bottle opener. This was done under a fume hood because the fumes inside the tube, NO, are very dangerous if inhaled. The contents were then poured into a $100 \mathrm{~mL}$ volumetric flask using a glass funnel. The digestion tube was washed three times with a prepared stock solution of $0.0001 \mathrm{M}$ $\mathrm{Hg}^{+2} / 0.1 \mathrm{M} \mathrm{KNO}_{3}$, as suggested by the CV27 voltammograph direction manual. After rinsing, the volume of the flasks was brought to $100 \mathrm{~mL}$ with this same stock solution. The samples were then covered and set aside until analysis.

The sample, in liquid form, is deoxygenated by bubbling nitrogen gas through it for 5-10 minutes stop degassing and divert the nitrogen gas to blanket the sample while simultaneously turning the 


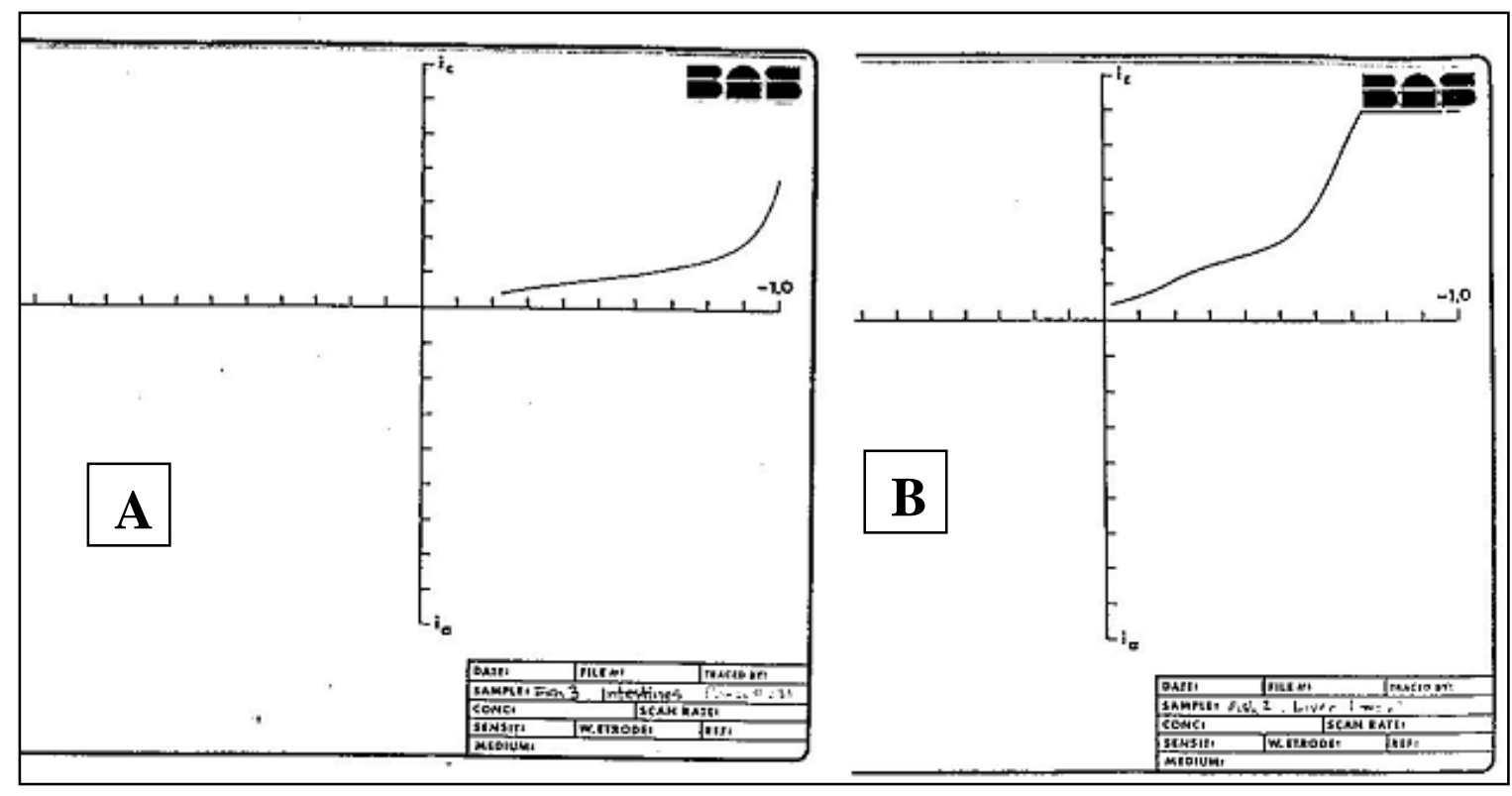

Figure 2. ASV Scans of Samples of Fish, A) intestines, B) Livers

magnetic stirrer on. Apply deposition potential for a carefully measured time interval of 8 minutes. At the end of this time, stirring was switched off and the solution was allowed to rest for 2 minutes.

All instrumental settings and conditions for measurements of all standard solutions and 60 samples were the same. All standard solutions (50, 100, 200, 400, $600 \mathrm{ppb}$ ) were made from $25 \mathrm{ppm}$ stand solution of $\mathrm{Pb}^{2+} / \mathrm{Cd}^{2+}$, diluted with $\mathrm{Hg}^{2+} / \mathrm{KNO}_{3}$ stock solution.

\section{RESULT}

Figure 1, represents a scan of 50 and $100 \mathrm{ppb}$ standard solutions and Figure $2 A$, is the scan of fish \#3 intestines and Figure 2B, fish \#2 liver. However, in testing, none of the samples showed a detectable level of lead or cadmium. This is attributed to: 1) Northern Pike are not bottom dwellers and thus would not be as highly exposed to sediments that most commonly contain trace metals; 2) the presence in this area of a major industry which typically produces contamination due to lead or cadmium is absent; and 3) conditions such as water temperature and time of year, $\mathrm{pH}$, etc. may have also reduced uptake and concentration. Overall, we can conclude that lead and cadmium concentrations in the intestines, liver, gill, and kidneys of Northern Pike (Esox lucius) is less than that which is detectable by use of ASV and is thus considered to be at a safe level.

\section{ACKNOWLEDGMENT}

A special thanks to Mr. Mark Stuble for his assistance in providing fish samples.

\section{REFERENCES}

1. Sures, B., H. Taraschewski, and E. Jackwerth, "Comparative Study of Lead Accumulation in Different Organs of Perch (Percafluviatilis) and Its Intestinal Parasite Acanthocephalus lucii," Bulletin of Environmental Contamination and Toxicology, Vol. 52, pp 269-273, 1994.

2. Coughlan, David J., Steven P. Gloss, and Joe Kubota, "Acute and Sub-Chrnic Toxicity of Lead to the Early Life Stages of Smallmouth Bass (Micropterus dolomieui)," Water, Air, and Soil Pollution, Vol. 28, pp 265-275, 1986.

3. "American Academy of Pediatrics Issues Treatment Guidelines for Lead Exposure in Children," American Family Physician, Vol. 51, No.3, pp I022-1023, September 1995. 
4. Dyer, Frank, “J. Clinical Presentation of the Lead-Poisoned Child on Mental Ability Tests," Journal of Clinical Psychology, Vol. 49, No.1, pp 94-101, January 1993.

5. Thacker, Stephen 8., Daniel A. Hoffinan, Jay Smith, Karen Steinberg, and Matthew Zack, "Effect of Low-level Body Burdens of Lead on the Mental Development of Children: Limitations of Meta-analysis in a Review of Longitudinal Data," Archives of Environmental Health, Vol. 47, pp 336346, Sept/Oct. 1992.

6. ATSDR, 2007, Toxicological Profile for Lead, Agency for Toxic Substances and Disease Registry, US Public Health Services, Atlanta, GA, USA.

7. Suresh, A., B. Sivaramakrishna, and K.Radhakrishnaiah, "Patterns of Cadmium Accumulation in the Organs of Fry and Fingerlings of Freshwater Fish (Cyprinus Carpio) Following Cadmium Exposure," Chemoshpere, Vol. 26, No.5, pp 945-953, 1993.

8. Nriagu, J.O. and J.B. Sprague, "Effects of Cadmium on Freshwater Fish from Cadmium in the Aquatic Environment," John Wiley and Sons, New York, NY, pp 139-169, 1987.

9. ATSDR, 2008, Draft Toxicological Profile for Cadmium, Agency for Toxic
Substances and Disease Registry, US Public Health Services, Atlanta, GA, USA.

10. ATSDR, 1993, Toxicological Profile for Cadmium, Agency for Toxic Substances and Disease Registry, US Public Health Services, Atlanta, GA, USA.

11. Boscher, A., Gobert, S., Guignard, C., Ziebel, J., L'Hoste, L., Gutleb, A, Cauchie, H., Hoffmann, L., Schmidt, G., "Chemical Contamination in Fish Species from Rivers in the North Luxemburg: Potential Impact on the Eurasian Otter (Lutra Lutra)," Chemosphere, Vol 78, pp 785-792, 2010.

12. Harrison, S. E., Klaverkamp, J. F., "Metal Contaminatin in Liver and Muscle of Northern Pike (Esox Lucius) and With Sucker (Catostomus Commersoni) and in sediments from Lakes Near Smelter at Filn Flon, Manotobia," Environmental Toxicology and Chemistry: An International Journal, Vol. 9, pp 941956, July 1990.

13. Friedrich, L. A., and Halden, N. M., "Determining Exposure History of Northern Pike and Walleye to Tailing Effluence Using Trace Metal Uptake in Otoliths," Environmental Science Technology, Vol. 44, pp 1551-1558, 2010.

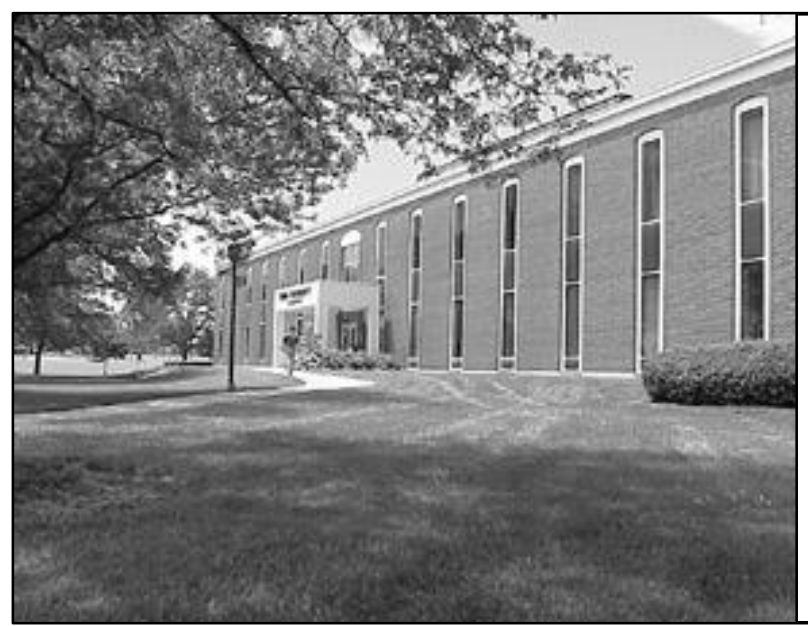

In 1946, Ohio University-Zanesville began a tradition of providing the education of a major research university, while maintaining the individualized attention associated with a small, liberal arts college. Students have access to more than $\mathbf{5 0}$ fulltime faculty who are highly qualified in their fields and have active research projects. Ohio University-Zanesville serves commuter students who seek associate, bachelor's or master's degrees, community education, or business and industry training. Our students join us right out of high school, from years of working on the job, or from other colleges, universities or technical schools. www.zanesville.ohiou.edu 


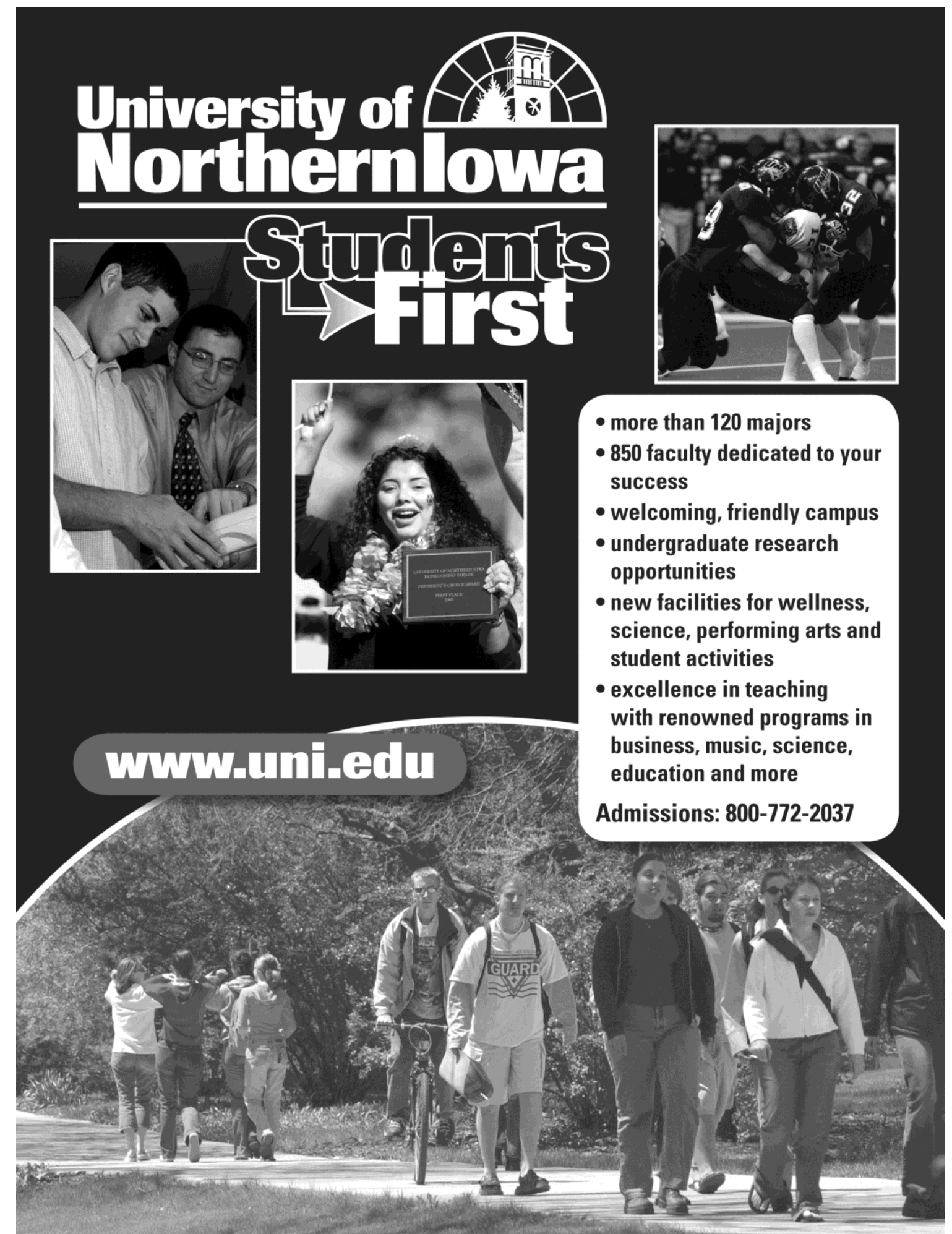

